\title{
A. Longo and D. Del Forno (eds.)
}

Argument from Hypothesis in Ancient Philosophy. Naples, Italy: Bibliopolis, 2011.

Pp. 482, €40 (pb.) ISBN 978-88-7088-597-2.

This volume contains eleven papers, divided into parts on (I) Plato and Aristotle (II) Hellenistic philosophy, and (III) late Platonism. After an introduction by Angela Longo, the contributions reflect a wide range of topics and approaches. The book's goal is 'to provide a wide view' of the subject, considering connections between hypothetical arguments, the hypothetical method, and other dialectical techniques; its coverage is uneven, but this is a decision by the editors. The introduction is useful, summarizing each chapter's most important claims in detail, although some chapters receive less attention than others. I shall mostly summarise here; space limits me to noting in passing where I found chapters well done, and where I found things to question. The book includes a bibliography, an index locorum, an index of ancient and medieval authors, and an index of modern authors.

First, Vassilis Karasmanis considers the relation between Hippocrates of Chios and Plato's use of hypotheses in the Meno, finding a close relation, but nevertheless a distinction, between the geometrical method of apagoge practiced by Hippocrates, and Plato's use of hypothesis in the Meno. There are subtle relations among the terms in play here, and Karasmanis exercises caution rather than too quickly identifying concepts that appear similar. I was mostly convinced by his claims, but would have found the conclusions more clear if stated at greater length.

Francesco Fronterotta gives a wide-ranging survey of 'hypothetical method' and 'dialectical method' in Plato. He draws a number of interesting connections among dialogues, although this seems more an introductory survey than a vehicle for new research.

Curzio Chiesa writes about the method of hypothesis in the Meno, and its relations to the theory of elenchus and anamnesis. I had some reservations about this chapter, although certain claims also struck me as worth further thought.

Paolo Crivelli contributes a lengthy consideration of Aristotle's views on syllogisms 'from a hypothesis,' asking 'which inferences rank among syllogisms from a hypothesis', for Aristotle. In reply, he gives an exemplary mapping of the options, and judiciously prefers one of these. Second, he asks what constitutes a syllogism from a hypothesis. He answers that syllogisms from a hypothesis seem to be those relying on inferences not based on mereological relations among the terms in the premisses and conclusion. The essay 
is long, but repays the efforts it demands; Crivelli's approach is careful and thorough.

Next, Jonathan Barnes gives us a lengthy and searching analysis of Stoic logical theory, to my mind the most rewarding chapter of the volume. The tricky relations between hypotheses (a class of sayables) and hypothetical arguments (a class of argument) are carefully teased apart. I had some difficulty keeping track of the many conclusions reached along the way, and which are rejected or qualified later in the piece. On Barnes' view, while the class of assertables (a type of sayable, according to the Stoics) is defined by the ability one has, in expressing them, to assert what they say, one need not assert anything by expressing them.

Lorenzo Corti looks at the skeptical attack on the dogmatic schools, starting from the claim that any alleged piece of knowledge must either be unjustified or else rely on justification by another piece of knowledge. In reply, he considers a dogmatic move claiming that some cases of knowledge are basic, neither having nor needing any argumentative justification. The article's approach is interesting and fruitful, although the moves proposed for one side or the other could sometimes be made more precise or improved.

Jean-Baptiste Gourinat looks at Alcinoos and Galen on hypotheses and the hypothetical method. He focuses on vocabulary more than others in this volume; the conclusions Gourinat reaches tend to be narrowly cast, and might be interestingly compared with those of Crivelli or Barnes.

Davide Del Forno contributes a stimulating study of the relation between the hypothetical method and other dialectical procedures according to Proclus. Dialectic includes definition, division, demonstration and analysis: why does Proclus consider these four inferior to the hypothetical method, and why do they find their completions in it? Del Forno's treatment is focused, imaginative, and convincing.

David Butorac looks at Proclus' view of the relation between the hypotheses of mathematics and those of dialectic. Not surprisingly (to my mind) Proclus emphasises the usefulness of mathematics as training while also firmly subordinating it to dialectic. He also distinguishes a middle and a higher sort of dialectic, the former again used for training minds, the latter allowing the human mind to reach the highest of which it is capable.

Alain Lernould shows how Proclus reads the Timaeus as a series of syllogisms. Proclus wants to show that Plato is no less a logician and scientist than Aristotle; since he accepts that science must be done via syllogisms, he feels compelled to uncover syllogistic structures in the Timaeus. This he does with great subtlety, revealing some genuine features of the text, but also much about the Neoplatonic syntheses of geometry and natural science. 
Finally, Franco Trabattoni gives a lucid exposition of Damascius' reasons for holding that the absolute principle of all cannot be spoken of without contradiction, and is somehow beyond the one and every other principle. Although Plotinus was committed to a similar first principle, and saw no contradiction in it, Damascius takes a different path. Trabattoni finishes by suggesting that Damascius' claim to be representing Plato's own views has more justification than one might think.

Specialists interested in ancient argument and logic will be most interested in these essays. While the book's topic is narrowly cast, several of its essays are of superb quality or approach their topics with imagination and originality, while a few are less ambitious or treat their subjects with less care. It is therefore to be recommended.

Brian D. Prince

University of Oxford brianprince498@gmail.com 